\title{
BEHAVIORAL STRATEGY AND THE STRATEGIC DECISION ARCHITECTURE OF THE FIRM
}

\begin{abstract}
This Special Issue explores the impacts of behavioral strategy on management practice. We believe that behavioral strategy can best contribute to management practice by shifting its focus from individual decision biases to the design of behaviorally-informed decision processes at the level of the firm. We identify three types of organizational decision processes, show how they interact with individual and group biases, and propose a model showing how managers can design and deploy these processes to shape the strategy of the firm. We introduce the papers of the Special Issue and discuss their contributions to the future of behavioral strategy.

$\underline{\text { Key words: }}$ Behavioral strategy, psychology, cognitive bias, strategic decision process
\end{abstract}

\section{INTRODUCTION}

The purpose of this Special Issue is to explore the impacts of behavioral strategy on management practice. Behavioral strategy "aims to bring realistic assumptions about human cognition, emotions, and social behavior to the strategic management of organizations and,

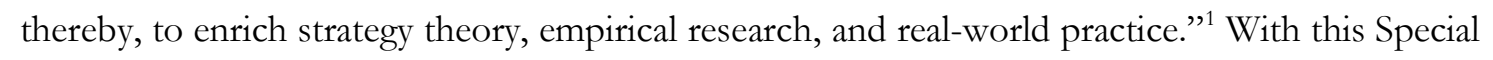
Issue we focus on the last of these aims, applying behavioral strategy to real-world practice.

Behavioral strategy has made significant inroads in academic research. A search for keywords related to behavioral strategy in the abstracts of Strategic Management Journal articles - terms like “cognition," "psychology," "behavior," and "emotion" - found an increase of $145 \%$ in six years: the terms appeared in $9.0 \%$ of abstracts in 2010 and $2012,12.8 \%$ of abstracts in 2014 , and $22.1 \%$ in $2016 .^{2}$ The percentage of SMJ articles in which the term "behavioral strategy" appeared in the full text was zero in 2010, 1.2\% in 2012, 1.8\% in 2014 and 4.6\% in 2016. A search of articles in Academy of Management Review and Academy of Management Joumal found that the term "behavioral strategy" appeared in the text of $1.4 \%$ of articles in $2010,3.4 \%$ in $2012,5.2 \%$ in 2014 , and $5.5 \%$ in 2016. Overall, the search term "behavioral strategy" appeared in $0.8 \%$ of articles published in SMJ, $A M J$, and $A M R$ in 2010, compared with $5.2 \%$ in 2016 - an increase of $550 \%{ }^{3}$

Is behavioral strategy making similar impacts on management practice? Yes and no. In public policy, governments are relying on "nudge units" to improve outcomes in areas such as tax 
compliance, energy conservation and healthcare. ${ }^{4}$ Popular books on cognitive biases and psychological pathologies are read by managers, and strategy consulting firms such as McKinsey \& Company use behavioral decision theory to help clients make better investment decisions. ${ }^{5}$ In three prominent journals read by practitioners - California Management Review, Harvard Business Review, and MIT Sloan Management Review - terms like "cognition," "psychology," "behavior," and “emotion" have increased, but not as dramatically as in academic journals, appearing in $10.5 \%$ of practitioner articles in $2010,10.4 \%$ in $2012,10.6 \%$ in 2014 , and $14.0 \%$ in 2016 . Overall there is progress, but behavioral strategy is far from realizing its full potential in management practice.

We believe that the main obstacle to progress is behavioral strategy's emphasis on individual cognitive biases. Experience has shown that people cannot easily address any of the known cognitive biases - status quo bias, confirmation bias, the planning fallacy, and such - no matter how much they learn about them. What managers really need is not a longer list of "Thou shalt nots" but a positive set of tools for designing a behaviorally-informed decision architecture of the firm. These tools should leverage what we know about cognitive and social psychology by linking the design of decision processes to desired outcomes at the level of the enterprise. A few scholars have offered suggestions of this kind, ${ }^{6}$ but behavioral strategy as a field has not completed the essential turn that would allow it to make significant contributions to practice; that is, pivoting away from individual cognitive biases, and toward the design of decision processes that capture what we know about cognitive and social psychology.

The papers in this Special Issue reflect this shift away from a "reductionist" view of behavioral strategy, in which individuals are the main level of analysis, ${ }^{7}$ to a more holistic understanding of strategy and human behavior in the context of the firm. Before introducing these papers, we examine why this shift is essential for bringing behavioral strategy to real-world practice, and we introduce a typology of the strategic decision processes that comprise the strategic architecture of the firm. We then show how managers can modify these processes, using behaviorally-informed decision processes as a powerful lever to direct the strategy of the 
firm. We conclude by introducing the papers of the Special Issue and showing their potential contributions to the future of behavioral strategy.

\section{The Problem With ReduCtionisM}

Research in behavioral strategy has been classified into three schools of thought: Reductionist, Pluralist and Contextualist. The Reductionist school is grounded in behavioral decision theory and behavioral economics, using experimental methods to study individual judgment and decision-making. ${ }^{8}$ The Pluralist school uses a variety of statistical and qualitative methods to study the wider decision environment of the firm, taking account of individual cognition (e.g., bounded rationality), social psychology (e.g., group identification, group conflict), and organizational phenomena such as learning and political bargaining. The Contextualist school favors qualitative or ethnographic methods, emphasizing the worldviews and perceptual frames of actors participating in particular organizational and strategic contexts.

With its emphasis on individual decision biases and heuristics, the Reductionist school has produced important insights, with real consequences for practicing managers. For example, researchers have linked excessive risk-taking in acquisitions to CEO overconfidence and hubris; ${ }^{9}$ they have shown how excess entrepreneurial market entry derives from myopic self-focus and the neglect of competition; ${ }^{10}$ how attending to sunk costs and anchoring on the status quo can distort resource allocations; ${ }^{11}$ and how executives justify their preferred strategies by constructing false analogies, or by making false inferences on limited or unrepresentative data. ${ }^{12}$

Reductionist experimental research is rigorous and cumulative, and the approach lends itself to classroom teaching and executive seminars. Through business schools, strategy consultancies, and authors of popular books, research on cognitive biases has reached a wide audience. ${ }^{13}$ In practice, this has allowed academics and consultants (including ourselves) ${ }^{14}$ to convey behavioral strategy research and practical advice with a consistent tone and message. 
The problem with Reductionism is that it cannot solve the main strategy problems executives actually face in complex organizations. There are several reasons for this. First, most decision biases arise from unconscious or evolutionary neuro-biological processes that lie beyond the awareness or control of decision makers. Biases are behaviorally and neurally hardwired to such an extent that decision makers cannot (or will not) abandon them in response to research findings or advice from consultants. Conscious or unconsciously, people do not want to lose their cognitive biases, but derive psychological comfort or practical value from them. ${ }^{15}$ Not all debiasing techniques are fruitless, but research findings suggest that interventions designed to remove individual decision biases are less effective than those designed to modify the environments in which decisions are made. ${ }^{16}$

Another problem is that cognitive biases studied in the lab are statistical phenomena, not universal truths. Some executive decisions may be relatively bias-free, but the unobservability of biases makes it hard to distinguish biased from unbiased decisions. We know, for example, that CEOs tend to overestimate the potential revenue synergies of acquisition targets; but we cannot know in advance, or in any particular case, that a CEO is guilty of this bias. The best we can say is "You probably have biases, so beware," which is of limited value to executives. ${ }^{17}$

The most serious problem, however, is that the Reductionist school does not address the core behavioral issues facing decision makers in organizations. Organizational decisions do not sum the biases of individuals, or mimic the biases of one individual, but effectuate a range of sociocultural and behavioral forces, including the psychological dynamics of small group behavior (e.g., top management teams), inter-group politics (e.g., divisional or departmental), systems and processes (e.g, structures and incentives that facilitate or impede strategy execution), and interactions with external boards and stakeholders. ${ }^{18}$ Individual biases play a role in organizational decisions, but not as a simple one-to-one mapping onto the strategy of the firm. ${ }^{19}$

Behavioral strategy can make significant contributions to management practice, but only by fully engaging the Reductionist, Pluralist and Contextualist perspectives. The Reductionist school 
cannot carry the load, and this is not its purpose. Organizational decisions entail large behavioral forces with significant consequences for strategic management practice. The next section proposes a typology of strategic decision processes in organizations, and shows how managers can use these processes to design a behaviorally-informed decision architecture of the firm.

\section{Strategic Decision Processes}

Strategic decision processes take many forms, including long-range strategic planning, shortrange executive problem-solving, bargaining within a top management team, inter-departmental and board politics, and many other routines and processes. We accept the view of Mintzberg and colleagues that these processes qualify as "strategic" when they become "important in terms of the actions taken, the resources committed, or the precedents set." ${ }^{\prime 20}$ This means that we are not concerned with one person or activity, but with the wider "decision architecture of the firm" that is, with the full range of actors and processes that shape decisions about the overall direction of the enterprise.

We know that individuals are susceptible to decision biases, but also that strategic decision processes can distort these biases or create new biases. Some decision processes counteract or neutralize individual decision biases; for example, a capital expenditure process that requires green lights at several levels of approval tends to dampen familiarity bias and favoritism. Other processes amplify individual biases; for example, a corporate executive allocating resources to business units may use past allocations as a key reference point, amplifying status quo bias. Some organizational processes create their own biases; for example, adding many layers of decision approval may create a collective degree of risk aversion that is not shared by any individual decision maker.

The crucial point for strategy executives is that, although people have limited conscious power over their own biases, they can design strategic decision processes to deal with individual and small-group biases before they become institutionalized as organizational decisions. This 
requires executives to understand how individual and group biases are influenced by organizational decision processes, and to design "decision architectures" that align strategic decisions with organizational goals.

Strategic decision processes tend to become routinized around a small number of repeated decision problems. ${ }^{21}$ For example, decision processes in pharmaceutical companies become routinized around the research and development pipeline, and (in many cases) mergers and acquisitions; decision processes in materials companies become routinized around resource exploration and capital investment decisions; and decision processes in fast-moving branded consumer companies become routinized around product and marketing decisions. This means that decision processes tend to follow patterns that allow us to identify a relatively small number of types.

In the following discussion we classify strategic decision processes into three types: investment processes, resource allocation processes, and blue sky processes. Investment processes involve major decisions with a "go" or "no-go" quality that require significant commitments to a particular course of action; resource allocation processes involve decisions with a "how much?" quality requiring the distribution of scarce resources; and blue sky processes involve open-ended decisions with a "what is possible?" quality calling for creative re-evaluation of product lines, markets, or the general direction of the enterprise. We describe these processes below and discuss behavioral issues and pathologies associated with each type. In subsequent sections we show how executives can address these issues by managing the decision architecture of the firm.

\section{Investment Processes}

Investment processes involve large commitments or strategic "bets" that start with a closedended question, often with a yes or no answer: Shall we launch this product? Hire this senior executive? Enter this market? Build this plant? Acquire this company? Sometimes they involve choices taken from a small number of options: Shall we enter market A or B? Develop product 
$\mathrm{X}$ or Y? Executives do not always refer to these as investment processes, but they have the essential qualities of investment decisions, namely the forecasting of costs and benefits and the evaluation of risk.

The essential outcome variable in investment decisions is the degree of risk; that is, managers need to design organizational processes to achieve the desired level of risk. ${ }^{22}$ In particular, these processes need to counteract individual biases in forecasting and risk estimation, which can lead to excess risk-aversion or risk-taking. Research shows that individuals facing large, one-off investment decisions tend to make overoptimistic forecasts and overconfident self-attributions that ignore the capabilities and responses of competitors. ${ }^{23}$ Executives become obsessed with their own ideas, and follow them against all evidence to the contrary - a phenomenon Peter Drucker called "investment in managerial ego." ${ }^{24}$ Because these biases are unconscious, people take on more risk than they intend, and more than they realize at the time of decision. If such biases passed unchecked into collective decision making, a company might invest too aggressively in new market entry, ${ }^{25}$ or overpay for acquisitions due to overestimation of synergies. ${ }^{26}$ As we show in the next section, executives need tools for designing investment processes that recognize these tendencies and produce the desired levels of risk.

On the other hand, executives often become attached to existing strategies or asset classes, displaying a degree of timidity or loss-aversion that produces insufficient risk-taking and investment. For example, decision makers often fail to consider the pooled risk of an entire portfolio of investments, causing risk-aversion in individual investment decisions, or in a series of investments staged over time. ${ }^{27}$ Equipped with a more nuanced behavioral view, executives can design processes that generate a degree of risk suited to their conscious risk preferences.

\section{Resource Allocation Processes}

Resource allocation processes involve questions about "how much?" Every strategy process requires resource allocation decisions, whether resources are being allocated across divisions, 
departments, geographic territories, product groups, or project teams. The archetypal example is the multi-business corporation allocating budgets and investment capital to strategic business units.

The essential outcome variable in resource allocation decisions is agility; that is, managers need to design organizational processes to achieve the desired degree of change and reallocation. In practice these processes need to counteract individual biases toward inertia. Empirical research shows that individual decision makers are reluctant to change existing resource allocations - that is, they adhere too closely to the status quo, and show too little agility in responding to external events. Executives unconsciously anchor resource allocations on static reference points - such as the previous year's budget - and thus unwittingly perpetuate past failures, or escalate commitment to failing courses of action. ${ }^{28}$ Incumbent firms change too little and too slowly in response to disruptive market entry, and multi-business corporations consistently fail to reallocate capital among business units as aggressively as capital markets. ${ }^{29}$

Biases toward inertia and the status quo pervade organizations at every level; for example, prospect theory shows that people are loss-averse, which means that managers of underperforming units will fight harder to defend existing resource allocations than managers of highperforming units will fight to appropriate their resources. Because these anti-agility biases are pervasive, they are not easily dampened by training or exhortation. A more effective approach is to design strategic decision processes that neutralize these biases and produce the desired levels of strategic agility.

\section{Blue Sky Processes}

Blue sky processes begin with open-ended strategy questions, usually involving high uncertainty, ill-defined problems, and the absence of clearly-articulated strategic options. They raise questions such as: How can we respond to an emerging technology? How can we accelerate company growth? What should our new organization look like? How should we compete? 
The essential outcome variable in blue sky processes is innovation; that is, managers need to design organizational processes that produce the desired degree of novelty or creativity. In behavioral terms, these processes need to counteract individual biases toward considering strategic options that are too few in number and too familiar to decision makers. Shareholders and managers alike often complain about lack of innovation, but these problems are deeply ingrained in the cognitive biases of decision makers. The first order of business in blue sky decisions is to think expansively about new ideas, alternatives, and courses of action. However, people tend to focus instead on repeating their own past successes (availability bias), avoiding their own past failures (the "hot stove effect"), making analogies to organizations they deem similar (often wrongly), and following the well-worn paths of successful companies (the "halo effect"). ${ }^{30}$ When one or two plausible-sounding ideas emerge, people quickly anchor on them or "satisfice," develop hopeful scenarios, and become psychologically attached to them. ${ }^{31}$ Idea generation stops and the blue sky process reduces to an investment process, choosing between two or three familiar options.

Experience suggests that blue sky processes produce too little innovation, failing to generate truly novel insights or action plans. They produce too few strategic options, and the options emerge too quickly from the narrow "inside view" of decision makers. Only through a behaviorally-informed strategic architecture can executives expect to overcome these biases and develop truly novel strategic actions.

Table 1 summarizes the three types of strategic decision processes, their key features and outcome variables. The next section shows how executives can design these processes to improve organizational decision making.

- INSERT TABLE 1 ABOUT HERE - 


\section{STRATEgIC DECISION ARCHITECTURE}

We believe that behavioral strategy can contribute to management practice by helping managers design decision processes that achieve desired levels of risk, agility and innovation. This requires an understanding of how individual and group biases operate on the three types of decision processes (summarized in Table 1), and of how organizational design can amplify, neutralize or dampen these biases.

We do not argue that firms should always strive to reduce risk, or to become more agile and innovative. Rather, we argue that the levels of risk, agility and innovation should be conscious strategic choices by executives, not unintended consequences of individual and group biases that operate behind the scenes to distort organizational decisions. Executives should strategize with a purpose, setting the desired outcomes of their decision processes and selecting the decision architectures best suited to achieving those outcomes. In this section we show how executives can design decision architectures that neutralize the tendencies of cognitive biases and achieve desired levels of risk, agility and innovation.

In designing decision processes, executives have a number of tools at their disposal. In the Sidebar we identify the seven most powerful levers for shaping the architecture of strategic decision processes. These are: Formality, Layering, Information, Participation, Incentives, Debate, and Closure. The Sidebar gives a brief description and example of each. In the following sections we show how strategists can use these levers to achieve desired outcomes in investment, resource allocation and blue sky processes.

\section{- INSERT SIDEBAR ABOUT HERE -}

\section{Designing Investment Processes to Calibrate Risk}

The key challenge facing executives in investment processes is to produce outcomes that carry an acceptable degree of risk. We do not suggest that one degree of risk is best, but that 
executives should use the levers of decision architecture to calibrate outcomes to the levels of risk most appropriate to their circumstances and risk preferences.

The most powerful levers for calibrating risk in investment processes are formality, layering, and closure. In large, one-off investment decisions, higher levels of these variables - more formalization, more decision layers, more stringent closure rules for decision approval - act as a brake on excess optimism and unintentional risk-seeking. For example, many companies lack established processes for evaluating mergers and acquisitions, and when an opportunity arises, executives and boards fall into overconfidence and wishful thinking. The best way to dampen the effects of "irrational exuberance" is to establish clear decision processes that calibrate organizational risk to the actual risk preferences of decision makers.

Conversely, if managers use highly formalized processes to make a sequence of small investment decisions, they may neglect the effects of risk-pooling, and thus stifle the organization by excess risk aversion. For these decisions, organizations achieve the desired level of risk by dialing back the key variables; that is, using less formality, fewer decision layers, and less stringent closure rules.

Although executives use these levers intuitively, decision processes can produce counterintuitive results, making it essential that executives grasp the behavioral nature of strategic decision architecture. For example, a private equity firm conducted an analysis showing that past investment decisions carried an unacceptable degree of risk. This happened despite a conservative closure rule in the investment committee: if two members (out of twelve) objected to a proposal, it was rejected. The firm responded with a more stringent closure rule, with proposals being rejected if only one member objected. However, this turned out to be less stringent than the previous rule. Requiring only one veto to stop a proposal put the lone objector in the spotlight, isolated from colleagues and exposed to censure. The "rule of one" made things worse, with team members avoiding confrontation and accepting risky investments. Consequently, the firm changed the closure rule so that it took four objectors to reject a 
proposal. This encouraged people to form coalitions and engage in livelier debates that ultimately produced a more satisfactory risk profile.

Executives can also calibrate the degree of investment risk by using other levers in the Sidebar. For example, they can dampen excess risk-taking by setting more stringent information requirements for investment proposals, or by requiring wider participation in the decision process. To deal with excess risk aversion in sequential decisions, firms can "batch" information for these decisions, improving the transparency of the overall risk profile. Using the levers in combination gives executives a flexible set of tools for managing risk, and better results than attempting to eliminate individual decision biases.

\section{Designing Resource Allocation Processes to Calibrate Agility}

The key challenge facing executives in resource allocation processes is to produce outcomes that carry an acceptable degree of agility. Although agility is widely praised as an unambiguous good, the truth is more complex. Organizational change is costly and destabilizing, and every strategic decision requires executives to balance the relative costs and benefits of enacting change or staying the course. ${ }^{32}$ We do not prescribe a particular balance of agility and continuity, but urge executives to use decision architecture to calibrate outcomes to desired levels of agility in their organizations.

The most powerful levers for calibrating agility in resource allocation are participation, information, and incentives. In large organizations, resource allocation processes often become routine and formalized, being linked with budgeting, planning, capital investment and other periodic processes. Resource allocation becomes automatic, much like accounting, risk management, and other standard operating procedures. When this happens, executives unconsciously adhere to the status quo and underestimate the need for change; or in some cases, lose sight of the strategic importance of resource allocation. When executives anchor resource 
allocations on formal routines in which past budgets serve as defaults, they achieve too little agility in resource reallocation.

Executives can address this tendency by altering patterns of participation in resource allocation decisions. For example, they can select participants with experience across several departments or lines of business; participants in close proximity to customers and suppliers; or participants not directly involved in the budgeting process.

Managers can also design new information requirements to encourage a more proactive approach to resource allocation. For example, companies can design new measurement and reporting systems focused on proportions of reallocation among divisions or departments. One consumer goods company created such a system by adding a tool for "re-based" budgeting, including a computer model showing allocations based purely on past performance data (revenues, growth and profitability). Managers were not required to adopt the computer's allocations, but the data shifted their attention to more objective, "re-based" reference points.

Organizations can also induce agility by using incentives. These include standard economic incentives - such as tying compensation to firm-level outcomes rather than to divisional or departmental growth - as well as more creative solutions. For example, executives can create new resource categories, setting aside funds unattached to any business unit and requiring unit managers to apply separately for these funds.

As with other processes, any of the levers in the Sidebar can be used to calibrate agility in resource allocation. For example, allowing more time for debate, or adopting more stringent closure rules, can impact the balance between agility and continuity. The crucial point is that the levers give strategists more control than is possible by focusing on individual decision biases.

\section{Designing Blue Sky Processes to Calibrate Innovation}

The key challenge facing executives in blue sky processes is to produce outcomes that carry an acceptable degree of innovation. Like agility, innovation is often portrayed as an unambiguous 
good, and non-innovation evil. But innovation incurs economic and social costs that strategists need to balance against the need to exploit existing strengths and to imitate the best practices of other firms - the classic balance between "exploration" and "exploitation." ${ }^{33}$ We do not argue for heedless innovation, but urge executives to use the seven levers to calibrate outcomes to achieve appropriate levels of innovation.

The most powerful levers for calibrating innovation in blue sky processes are debate, participation, and incentives. Many individual biases militate against strategic innovation, so organizations that neglect the design of blue sky processes tend to repeat old strategies, anchor quickly on familiar options, neglect new options, and take an "inside view" that ignores new technologies, market opportunities, changing customer preferences, and the actions of actual or potential competitors.

Organizations can enhance innovation by broadening both the rules of debate - that is, their implicit or explicit patterns of strategy conversation - and the bases of participation. For example, blue sky processes often require managers to provide reasons that fit the worldviews of their superiors, implicitly discouraging causal arguments supported by evidence. Unfortunately, reason-based arguments tied to existing worldviews amplify the tendency to stagnation. For example, research shows that investment managers tend to prefer glamor stocks that are "rhetorically safe" - that is, supported by reasons their superiors accept - over less familiar choices that yield higher returns at lower risk. The researchers concluded: "If groups engage in dynamic processes that lead them to focus on alternatives described by good reasons,.... the process we document may yield alternatives that have notable disadvantages but that happen to come attached to a good reason."34

Executives can break these dysfunctional patterns by designing strategic debates that encourage people to advocate innovations supported by causal arguments and evidence, irrespective of existing worldviews. Such processes nearly always require organizations to broaden participation in strategic debates, often going outside the organization. For example, 
gaming company Valve Corporation makes extensive use of crowdsourcing, incentivizing gamers to propose new products and using an internal system of "social proofs," in which people form coalitions around new ideas and marshal evidence to demonstrate their market potential. ${ }^{35}$ Crucially, these decision processes encourage innovation through an increased tolerance for dissent. For example, Google insists on "discord plus deadline," Amazon expects people to "have backbone, disagree and commit," and McKinsey \& Company urges every consultant and employee to "uphold the obligation to dissent."

The key to calibrating innovation in blue sky processes is to measure past innovation, make an honest assessment of innovation performance, and design decision environments calibrated to organizational goals. Whether the problem lies in too little innovation or heedless innovation, any or all of the seven levers can help strategists manage innovation without having to remediate the individual biases of decision makers.

\section{CONCLUSION}

To contribute to management practice, behavioral strategy needs to show managers how to make better decisions in organizational settings. Behavioral decision research shows that individual cognitive biases can distort decision making, but does not show how managers can predict or manage their impacts in organizations. Individual biases are unconscious and persistent mental events, and unpromising targets for control or intervention. We believe that organizational strategists should focus instead on decision processes at the level of the organization, neutralizing the impacts of individual biases by using the levers of decision architecture to calibrate decision outcomes to organizational goals. The descriptive summaries in Table 1, the Sidebar and the text comprise a basic toolkit for managing these processes.

At the same time, organizations are complex systems and strategic decision architecture is far from simple. Decision processes sit within organizational histories and cultures that produce 
surprising feedback loops and unintended effects. In putting these ideas into practice, strategists should be aware of complications and pitfalls, as well as opportunities.

For example, the three decision processes overlap to some degree, giving rise to hybrid processes. Investment decisions inevitably involve resource allocations, or can be construed as blue sky processes. Executives need to exercise judgment in defining the decision process and choosing the right levers for intervention. This is a potential pitfall but also an opportunity, since framing the decision process provides executives with another design lever for strategy processes: classifying the decision as an investment process puts the spotlight on risk and invites scrutiny of one or two options; framing it as resource allocation emphasizes agility (or inertia) and the broader context of resource distribution; and framing it as a blue sky process draws attention to innovation (or stagnation) and the "open-ended" nature of the decision. Depending on organizational goals, executives may prefer to draw attention to risk propensity, resource agility, or innovation.

In an earlier section, we noted that individual decision biases are statistical phenomena, not universal truths. Because we cannot directly observe mental events, we find out about biases after the fact, by observing their effects. So a manager might reasonably ask: If our top executives are relatively unbiased, will using the seven levers overcompensate for biases that are not, in fact, present? Will we end up with too much risk aversion in large investment decisions? Costly agility in resource allocation decisions? Heedless innovation in blue sky processes?

These questions shed light on an important consequence of taking a behavioral approach to strategy; namely, the need for organizations to improve measurement systems for key strategic outcomes such as investment risk, resource agility and strategic innovation. If properly designed, these measurement systems will tell managers what they need to know about the impacts of individual and group biases. If they show that an organization is consistently hitting its targets for all outcomes, then either executives are relatively unbiased, or the organization's decision processes are already neutralizing executive biases. Either way, the best policy for managers is to 
know the tendencies of executive decision biases; to develop systems for measuring investment risk, resource agility and strategic innovation; and to use the tools of decision architecture to manage outcomes.

\section{CALIFORNIA MANAGEMENT REVIEW SPECIAL ISSUE: Behavioral Strategy and Management Practice}

In issuing the original Call for Papers more than two years ago, we defined the scope of the Special Issue as follows:

The purpose of this Special Issue of California Management Review is to examine what happens when Behavioral Strategy meets management practice. If decision makers are not rational in a strict economic sense, what are the consequences for competition, organization, and strategy? In a psychologically-informed world, how should executives think about decision processes, market entry, resource allocation, new strategic initiatives, innovation and strategy execution? If decision environments are filled with cognitive biases, emotions, ideologies, social processes, and political conflicts, how can managers best allocate resources and position the firm for competitive advantage?

The Call for Papers invited people to submit 1,500-word proposals from which we, as coeditors, chose a subset for development into full papers for the Special Issue. We were fortunate to receive a very large number of proposals, from which we chose 15 for development into full papers. When review processes were complete for all papers, the six papers that appear in this issue were chosen for publication.

We want to thank everyone who submitted a proposal to the Special Issue, as well as those who kindly reviewed submissions. We received more good proposals than we could develop or publish, and had to make very difficult calls on papers we would like to have published. In the end, we extend our gratitude to all authors and reviewers for their patience with the review process, and we hope that the Special Issue has achieved its purpose of bringing behavioral strategy theory and research to the practice of strategic management.

We believe that each of the six published papers contains at least one big idea that contributes uniquely to this purpose. The paper by Wiersema and Weber combines a range of behavioral perspectives - including expectancy theory, attribution theory, and motivation theory - to 
explain how and why some CEOs manage to survive unfavorable events while others are dismissed. The paper sheds light not only on CEO dismissal but on crucial problems such as corporate reputation management and the responsibilities of corporate boards.

The paper by Smit and Kil focuses on decision biases in acquisition decisions, particularly the neglect of uncertainty due to executive hubris and overconfidence. Although acquirers could reduce investment risk by acquiring minority stakes, or "toeholds," in target companies, these arrangements account for only five percent of all acquisitions. The authors provide a real-options decision process to help managers make better acquisition decisions.

Mazutis and Eckardt examine an issue out of the latest headlines, namely inertia in corporate decisions in relation to global climate change. The authors argue that the causes of corporate inertia go beyond economic disincentives and the "tragedy of the commons," involving cognitive biases such as gain/loss framing, over-optimism, hyperbolic discounting, and external locus of control. Interpreting the problem through a psychological lens allows the authors to propose corporate-level behavioral solutions to climate change inertia.

The paper by Healey and Hodgkinson explores the role of emotions in strategic decision making, particularly in companies facing the need for rapid innovation in dynamic environments. Drawing on research in experimental psychology and cognitive neuroscience, the authors provide managerial checklists for managing the emotional dynamics of sensing, seizing, and transforming market opportunities.

Liu and colleagues draw on behavioral research to show how managers can learn from the "nudges" and "behavioral insights" that have proven so successful in government and public policy decision making. Recognizing the persistence of individual cognitive biases, the authors offer an applied framework and two case studies showing how managers can engage good biases to overcome bad biases, and engineer decision environments for better results.

The paper by Powell takes a different approach, arguing that strategists systematically overstate the intellectual difficulties of strategy-making while underestimating the challenges of 
putting strategies into practice. This "chess syndrome" gives rise to market opportunities for companies that diligently execute a small number of fundamental activities critical to industry success. Powell offers a managerial framework for identifying, measuring and executing the fundamentals of business success.

We hope you enjoy reading the Special Issue. In addition to those who submitted and reviewed papers, we give special thanks to Kora Cypress and her team at CMR, and to Editor-inChief David Vogel, all of whom worked patiently to bring the Special Issue to fruition. 


\section{Table 1: Three Types of Strategic Decision Processes}

\begin{tabular}{|c|c|c|c|}
\hline Type of Process $\rightarrow$ & Investment & Resource Allocation & Blue Sky \\
\hline Examples & $\begin{array}{l}\text { Acquisition } \\
\text { Product launch } \\
\text { Capital expenditure }\end{array}$ & $\begin{array}{l}\text { Corporate SBUs } \\
\text { Department budgets } \\
\text { Project teams }\end{array}$ & $\begin{array}{l}\text { New strategies } \\
\text { New markets } \\
\text { Organization design }\end{array}$ \\
\hline Key Question & Go or no go? & How much? & What is possible? \\
\hline Outcome Variable & Degree of Risk & Degree of Agility & Degree of Innovation \\
\hline $\begin{array}{l}\text { Behavioral } \\
\text { Tendency }\end{array}$ & $\begin{array}{l}\text { Risk-seeking in large } \\
\text { one-off decisions } \\
\text { Risk-aversion in small } \\
\text { sequential decisions }\end{array}$ & $\begin{array}{l}\text { Inertia } \\
\text { Status quo } \\
\text { Inability to reallocate }\end{array}$ & $\begin{array}{l}\text { Too few options } \\
\text { Familiar options } \\
\text { Premature satisficing }\end{array}$ \\
\hline Individual Biases & $\begin{array}{l}\text { Overconfidence } \\
\text { Delusional optimism } \\
\text { Competition neglect }\end{array}$ & $\begin{array}{l}\text { Anchoring } \\
\text { Status quo bias } \\
\text { Escalation }\end{array}$ & $\begin{array}{l}\text { Inside view } \\
\text { Misleading analogies } \\
\text { Halo effect }\end{array}$ \\
\hline
\end{tabular}




\section{Sidebar: \\ Seven Levers for Designing Strategic Decision Processes}

1. Formality. Executives have wide discretion in setting the degree of formality in a decision process. Formalized processes typically involve strategic planning teams, formal meetings, extensive data-gathering, comprehensive formal analysis, and documentation in manuals, operating procedures, and strategy playbooks. Formal and informal processes have been extensively described and researched in strategic management. ${ }^{36}$

2. Layering. Strategic decisions can be shaped by adding or removing decision layers, or by assigning decision approvals to different people or roles; for example, banks manage loan risk by setting the number and nature of approval levels for loans of various sizes.

3. Information. Decision processes use information rules that determine the amount and nature of information required for decision making. These specify the kinds of data and analysis that an organization expects before a decision can be considered, along with formats for presentation and analysis.

4. Participation. Strategic outcomes of decision processes are shaped by those involved in discussing and making the decision. Highly centralized processes involve a small number of top managers (or only one). Decentralized processes may involve representatives of divisions, departments, functional areas, project teams, or external stakeholders. The nature and extent of participation, and the degree of empowerment of these participants, is an important design variable for managers.

5. Incentives. We are not concerned here with financial incentives that induce general contributions to the organization, but with the financial and non-financial motives and interests that people bring with them as participants in decision processes. For example, a VP of marketing may bring an aspiration to become CEO; division or department managers may bring loyalties to those parts of the business, or antagonisms to each other; a top scientist may bring resentment about past decisions. It is essential for executives to manage the social and behavioral character of decision processes.

6. Debate. How do strategy conversations unfold in the organization? In some companies, one or two people do all the talking, but in others executives give everyone a voice. Some decision processes feature conflict and discord (productive or otherwise), while others fall into groupthink and consensus. Although the rules of strategy debate are often unspoken and culturally-driven, they are a powerful design variable for managers.

7. Closure. How do decisions finally get made? In some organizations, it is unclear whether a course of action has been decided; in others, there are clear voting and decision rules (such as majority rule, or a single-veto rule); and in others still, an executive makes the call and all input is consultative. Closure rules can depend on the type of decision; for example, "go or no-go" decisions tend to elicit more formal voting procedures. Like other levers, closure rules can amplify or dampen the degree of risk, agility and innovation. 


\section{Notes}

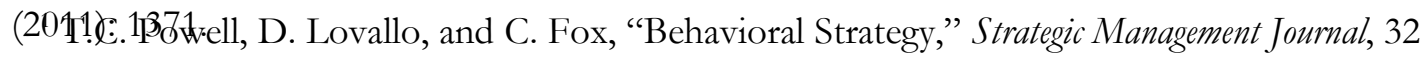

2

The authors appreciate the assistance of Miao Wang in gathering these data. The complete list of keyword search terms was: cognition, cognitive, psychology, psychological, behavior, behavioral, emotion, emotional. We also searched the abstracts of $A M R$ and $A M J$ for these terms, but the results were less meaningful, since $A M R$ and $A M J$ publish research on organizational behavior, leadership, and other topics that use these terms. In 2016, 32.0\% of articles in $A M R$ and $A M J$ (combined) included one of these terms in the abstract, compared with $25.5 \%$ in 2014 .

3 These advances in academic research are largely the fruit of activity in the Academy of Management (AOM) and Strategic Management Society (SMS). AOM pre-conference workshops on behavioral strategy began in 2007, and a panel of scholars gave a well-attended plenary session in the 2012 AOM meetings in Boston (the panel was chaired by Joe Porac and the panellists were Don Hambrick, Dan Lovallo, Thomas Powell and Richard Rumelt). In 2008, a Call for Papers for an SMJ Special Issue on Psychological Foundations of Strategic Management generated a record number of submissions. The Special Issue was published in December 2011, with the lead paper calling for the formation of a new Strategic Management Society Interest Group. In 2012, nine launch committee members and 70 founding members formally proposed this group to the SMS board, and the SMS Interest Group on Behavioral Strategy was launched at the annual meetings in Atlanta in 2013 (members of the Launch Committee were Richard Bettis, Jerker Denrell, Christina Fang, Giovanni Gavetti, Daniel Levinthal, Dan Lovallo, Joe Porac, Thomas Powell, and Zur Shapira). The SMS Interest Group is now an integral part of the SMS research community, and a significant hub of resarch activity within and beyond SMS.

For example, see: D. Halpern, Inside the Nudge Unit: How Small Changes Can Make a Big Difference (London: W.H. Allen, 2015); R.H. Thaler, Misbehaving: How Economics Became Behavioral (New York: W.W. Norton \& Company, 2015).

5

For example: M. Lewis, The Undoing Project: A Friendship that Changed the World (New York: W.W. Norton \& Company, 2017); D. Kahneman, Thinking, Fast and Slow (New York, NY: Farrar, Straus and Giroux, 2011); R.H. Thaler and C.R. Sunstein, Nudge: Improving Decisions About Health, Wealth, and Happiness (New Haven CT: Yale University Press, 2008).

6

For example: P.E. Tetlock, "Cognitive Biases and Organizational Correctives: Do Both Disease and Cure Depend on the Politics of the Beholder?," Administrative Science Quarterly, 45/2 (2000): 293-326.

C. Heath, R.P. Larrick, and J. Klayman. "Cognitive Repairs: How Organizations Compensate for the Shortcomings of Individual Learners," Research in Organizational Behavior, 20 (1998): 1-37.

Powell, Fox and Lovallo (2011) identified three branches of academic research in behavioral strategy: reductionist, pluralist, and contextualist. See, T.C. Powell, D. Lovallo, and C. Fox, "Behavioral Strategy," Strategic Management Joumal, 32 (2011): 1369-1386.

8

The three strands are described in detail, with examples and historical antecedents, in T.C. Powell, D. Lovallo, and C. Fox, "Behavioral Strategy," Strategic Management Journal, 32 (2011): 1369-1386. 
${ }^{9}$ For example: R. Roll, "The Hubris Hypothesis of Corporate Takeovers,", Journal of Business, 59/2 (1986): 197-216; M.L.A. Hayward and D.C. Hambrick, "Explaining the premiums paid for large acquisitions: Evidence of CEO hubris," Administrative Science Quarterly, $42 / 1$ (1997): 103127.

${ }^{10}$ See C. Camerer and D. Lovallo, "Overconfidence and Excess Entry: An Experimental Approach," The American Economic Review, 89/1, (1999): 306-318.

${ }^{11}$ See S. Hall, D. Lovallo, and R. Musters, "How to Put Your Money Where Your Strategy is," McKinsey Quarterly (March 2012): 11.

${ }^{12}$ For example: P.M. Rosenzweig, The Halo Effect and the Eight Other Business Delusions that Deceive Managers (New York, NY: Free Press, 2007).

${ }^{13}$ For example: D. Ariely, Irrationally Yours (New York: Harper Perennial, 2015); R.H. Thaler, Misbehaving: How Economics Became Behavioral (New York: W.W. Norton \& Company, 2015); M. Lewis, The Undoing Project: A Friendship that Changed the World (New York: W.W. Norton \& Company, 2017).

${ }^{14}$ For example: D. Kahneman, D. Lovallo, and O. Sibony, "The Big Idea: Before You Make That Big Decision," Harvard Business Review, 89/6 (2011): 50-60.

${ }^{15}$ G. Gigerenzer and W. Gaissmaier, "Heuristic Decision Making," Annual Review of Psychology, 62 (2011):451-482.

${ }^{16}$ For example: K.L. Milkman, D. Chugh, and M.H. Bazerman, "How Can Decision Making Be Improved?," Perspectives on Psychological Science, 4/4 (2009): 379-383; J.B. Soll, K.L. Milkman and J.W. Payne, "A User's Guide to Debiasing," The Wiley Blackwell Handbook of Judgment and Decision Making, (New York: John Wiley and Sons, 2015), p. 684; D. Kahneman, Thinking, Fast and Slow (New York, NY: Farrar, Straus and Giroux, 2011).

${ }^{17}$ See P.M. Rosenzweig, Left Brain, Right Stuff: How Leaders Make Winning Decisions (New York: PublicAffairs, 2014).

${ }^{18}$ For example, see T. Hutzschenreuter, and I. Kleindienst, "Strategy Process Research: What Have We Learned and What Is Still to Be Explored," Journal of Management, $32 / 5$ (2006):673620; C.R. Sunstein and R. Hastie, Wiser: Getting beyond Groupthink to Make Groups Smarter (Cambridge, MA: Harvard Business Press, 2015).

In existing research, the problem of aggregating individual decision making to the level of the organization has been addressed in three ways. The first is to make direct analogies from individual biases to company biases; arguing, for example, that a firm suffers from "illusion of control" [see R. Durand, "Predicting a Firm's Forecasting Ability: The Roles of Organizational Illusion of Control and Organizational Attention," Strategic Management Journal, 24/9 (2003): 821838]. The second is to treat decision makers not as individuals but as a population whose demographic characteristics tend to produce certain kinds of decisions. For example, the upper echelons tradition holds that: (1) Choices are influenced by the preferences of powerful actors (e.g., the top management team); (2) These preferences correlate with observable, mostly demographic characteristics; and (3) These characteristics predict strategic and organizational outcomes at the level of the firm [see D.C. Hambrick and P.A. Mason, "Upper Echelons: The Organization as a Reflection of Its Top Managers," Academy of Management Review, 9/2 
(1984):193-206; M.A. Carpenter, M.A. Geletkanycz and W.G. Sanders, "Upper Echelons Research Revisited: Antecedents, Elements, and Consequences of Top Management Team Composition," Journal of Management, 30/6 (2004): 749-778.]. This approach is useful but has been criticized on grounds that observing correlations between managerial demographics and firm choices, without a clear description of mechanisms through which the former produce the latter, "sacrifice[s] construct validity for measurement reliability" [see R.L. Priem, D.W. Lyon and G.G. Dess, "Inherent Limitations of Demographic Proxies in Top Management Team Heterogeneity Research," Journal of Management, 25/6 (1999):935-953.].

The third approach, which we consider more promising, is to focus not on organizations or individuals, but on processes by which individuals affect the strategic choices of firms. This is consistent with the "microfoundations" approach, which argues that "organizational analysis should be fundamentally concerned with how individual-level factors aggregate to the collective level" [ J. Barney and T. Felin, "What Are Microfoundations?," Academy of Management Perspectives, 27/2 (2013): 145]. As Devinney points out, this perspective has particular relevance for practicing managers: "Ultimately, managers are concerned with how lower-level actions and activities (...) affect the performance of the organization" [T.M. Devinney, "Is Microfoundational Thinking Critical to Management Thought and Practice?," Academy of Management Perspectives, $27 / 2$ (2013): 83]. This approach echoes the original call of behavioral strategy to researchers: to address "the scaling problem [that] is far from solved, and often improperly framed (...), the question is how we integrate individual and collective psychology in organizations to produce a social psychology of behavioral strategy" [T.C. Powell, D. Lovallo, and C. Fox, "Behavioral Strategy," Strategic Management Journal, 32 (2011): 1376.].

${ }^{19}$ K.M. Sutcliffe and G. McNamara, "Controlling Decision-Making Practice in Organizations," Organization Science, 12/4 (2001): 484-501.

${ }^{20}$ H. Mintzberg, D. Raisinghani and A. Theoret, "The Structure of 'Unstructured' Decision Processes," Administrative Science Quarterly, 21 (1976): 246-275.

${ }^{21}$ M.D. Cohen, R. Burkhart, G. Dosi, M. Egidi, L. Marengo, M. Warglien and S.G. Winter, "Routines and other Recurring Action Patterns of Organization: Contemporary Research Issues," Industrial and Corporate Change, 5/3 (1996), pp. 653-698; D.J. Teece, G. Pisano and A. Shuen, "Dynamic Capabilities and Strategic Management," 18/7 (1997): 509-533.

${ }^{22}$ Of course, returns are also important in investment decisions; but our aim in the paper is to focus on variables over which managers have a significant degree of control, and for which we have clear evidence of behavioral biases and heuristics.

${ }^{23}$ D. Kahneman and D. Lovallo, "Timid Choices and Bold Forecasts: A Cognitive Perspective on Risk Taking," Management Science 39/1 (1993): 393-413.

${ }^{24}$ P. Drucker, Managing for Results (New York, NY: Harper \& Row, 1964).

${ }^{25}$ S. Artinger and T.C. Powell, "Entrepreneurial Failure: Statistical and Psychological Explanations,” Strategic Management Journal, 37 (2016): 1047-1064.

${ }^{26}$ See R.F. Bruner "Does M\&A Pay? A Survey of Evidence for the Decision-Maker," Journal of Applied Finance, 12/1 (2002): 48-68; D.R. King, D.R. Dalton, C.M. Daily and J.G. Covin, "MetaAnalyses of Post-Acquisition Performance: Indications of Unidentified Moderators," Strategic Management Journal, 25/2 (2004): 187-200. 
${ }^{27}$ D. Kahneman and D. Lovallo, "Timid Choices and Bold Forecasts: A Cognitive Perspective on Risk Taking," Management Science 39/1 (1993): 393-413.

${ }^{28}$ See: D. Bardolet, C.R. Fox and D. Lovallo, "Corporate Capital Allocation: A Behavioral Perspective,” Strategic Management Journal, 32 (2011): 1465-1483.

${ }^{29}$ J.C. Stein, "Agency, Information and Corporate Investment," in Handbook of the Economics of Finance, 1 (2003): 111-165. See also S. Hall, D. Lovallo and R. Musters, "How to Put Your Money Where Your Strategy is," McKinsey Quarterly, March 2012, p. 11.

${ }^{30}$ See for example: J. Denrell and C. Fang, "Predicting the Next Big Thing: Success as a Signal of Poor Judgment," Management Science 56/10(2010): 1653-1667; P.M. Rosenzweig, The Halo Effect and the Eight Other Business Delusions that Deceive Managers (New York, NY: Free Press, 2007); J. Denrell and J.G. March, "Adaptation as Information Restriction: the Hot Stove Effect. Organization Science 12/5(2001): 523-538; D. Lovallo, C. Clarke and C. Camerer, "Robust Analogizing and the Outside View: Two Empirical Tests of Case-Based Decision Making," Strategic Management Journal, 33/5 (2012): 496-512.

${ }^{31}$ C. Heath and D. Heath, Decisive: How to Make Better Choices in Life and Work (New York, NY: Crown Business, 2013).

32 See, for example: P. Ghemawat and P. del Sol, "Commitment versus Flexibility?" California Management Review, 40/4 (1998): 26-42; T. Felin and T.C. Powell, "Designing Organizations for Dynamic Capabilities," California Management Review 58/4 (2016): 78-96; G. Pacheco-de-Almeida, J. Henderson and K. Cool, "Resolving the Commitment vs. Flexibility Trade-Off: The Role of Resource Accumulation Lags," Academy of Management Journal, 51/3 (2008): 1498-1526.

33 The classic statement being: J.G. March, "Exploration and Exploitation in Organizational Learning," Organization Science, 2/1 (1991): 71-87.

${ }^{34}$ B.M. Barber, C. Heath and T. Odean, "Good Reasons Sell: Reason-Based Choice Among Group and Individual Investors in the Stock Market," Management Science, 49/12 (2003): 16361652.

${ }_{35}$ T. Felin and T.C. Powell, "Designing Organizations for Dynamic Capabilities," Califormia Management Review 58/4 (2016): 78-96.

${ }^{36}$ See, for example: N. Rajagopalan, A.M.A. Rasheed and D.K. Datta, "Strategic Decision Processes: Critical Review and Future Directions," Journal of Management, 19/2 (1993):349-384; J.W. Fredrickson, "The Comprehensiveness of Strategic Decision Processes: Extensions, Observations, Future Directions," Academy of Management Journal, 27 (1984): 445-466; and T.C. Powell, "Strategic Planning as Competitive Advantage," Strategic Management Journal, $13 / 7$ (1992): 551-558. 